\title{
Modulatory effects of feeding pregnant and lactating mice Rhodiola kirilowii extracts on the immune system of offspring
}

\author{
SŁAWOMIR LEWICKI ${ }^{1}$, BARBARA JOANNA BAŁAN ${ }^{2}$, EWA SKOPIŃSKA-RÓŻEWSKA ${ }^{3,4}$, \\ ROBERT ZDANOWSKI ${ }^{1}$, MARTA STELMASIAK ${ }^{2}$, ŁUKASZ SZYMAŃSKI $^{4}$ and WANDA STANKIEWICZ ${ }^{4}$ \\ ${ }^{1}$ Department of Regenerative Medicine, Military Institute of Hygiene and Epidemiology, 01-163 Warsaw; Departments of \\ ${ }^{2}$ Immunology, Biochemistry and Nutrition and ${ }^{3}$ Pathomorphology, Center for Biostructure Research, \\ Warsaw Medical University, 02-004 Warsaw; ${ }^{4}$ Department of Microwave Safety, \\ Military Institute of Hygiene and Epidemiology, 01-163 Warsaw, Poland
}

Received May 5, 2016; Accepted June 8, 2016

DOI: $10.3892 /$ etm.2016.3759

\begin{abstract}
Plants of Rhodiola genus are medicinal herbs that have a number of therapeutic properties, including anti-inflammatory and immunomodulatory activity. The present study aimed to determine whether the use Rhodiola kirilowii as an immunostimulant during pregnancy has an adverse effect on the development of the offspring immune system. Following mating, pregnant mice were placed in three groups that were fed during pregnancy and lactation with $R$. kirilowii aqueous extract (RKW; $20 \mathrm{mg} / \mathrm{kg}$ ), R. kirilowii $50 \%$ hydro-alcoholic extract (RKW-A; $20 \mathrm{mg} / \mathrm{kg}$ ) or water (control group), receiving water. Following birth, offspring were given six weeks to develop prior to evaluation of their immune system. Morphometric and morphological examination of the spleen did not reveal any abnormalities or differences between the experimental and control groups. However, both RKW and RKW-A splenic lymphocytes presented a diminished proliferative response to concanavalin A. RKW spleen lymphocytes demonstrated increased metabolic activity following phytohaemagglutinin (PHA) stimulation, which was associated with a higher percentage of cluster of differentiation 4 positive spleen cells and lower interleukin-17a (IL-17a) serum concentration. The RKW-A group exhibited a diminished proliferative response of spleen lymphocytes to PHA and lipopolysaccharide (LPS), and increased serum concentrations of IL-10 and tumor necrosis factor- $\alpha(\mathrm{TNF}-\alpha)$. The progeny of mice fed with RKW-A extract demonstrated a significantly lower level of anti-SRBC antibody following immunization compared with progeny of the control $(\mathrm{P}=0.0305)$ and $\mathrm{RKW}$ $(\mathrm{P}=0.0331)$ groups. In conclusion, caution is recommended in
\end{abstract}

Correspondence to: Dr Barbara Joanna Bałan, Department of Immunology, Biochemistry and Nutrition, Warsaw Medical University, Oczki 3, 02-004 Warsaw, Poland

E-mail: bbalan@wum.edu.pl

Key words: mice, pregnancy, Rhodiola kirilowii, progeny, immune response the use of RKW and RKW-A extracts as immunostimulants in pregnancy.

\section{Introduction}

The genus Rhodiola consists of numerous species. The best known is $R$. rosea (1-3). Less reported in Europe are other members of this genus, $R$. quadrifida and $R$. kirilowii. Plants of Rhodiola genus, a member of the Crassulaceae family, are traditionally used in Asiatic medicine for their adaptogenic and anti-inflammatory properties, and have been recognized as immunomodulators in the past few decades $(4,5)$. In addition, these plants exhibit inhibitory effects against a number of pathogens without the involvement of an immune system. It has been reported that extracts from $R$. rosea inhibit Clostridium perfringens and influenza virus neuraminidases in vitro (6). Moreover, $R$. rosea extract inhibits the replication of dengue virus, vesicular stomatitis virus and coxsackievirus B3 (7-9). Plants from Rhodiola genus are useful in bacterial infections, particularly those displaying antibiotic resistance. Cybulska et al (10) demonstrated that addition of $R$. rosea extract to Neisseria ghonorrhea culture inhibits its growth in vitro. Based upon these findings, it is possible that Rhodiola-based therapeutic agents may be useful adjuvants or alternatives to antibiotics in the treatment of viral/bacterial infections during pregnancy.

Previous studies have investigated the immunotropic activity of alcoholic and aqueous extracts of roots and rhizomes of Rhodiola plants in mice, rats and pigs. During the initial investigation (11), not a large quantity of information was available about the immunotropic activity of Rhodiolas. Further studies showed that the majority of Rhodiola extracts stimulated immunity $(12,13)$. The present study investigates the effects of aqueous Rhodiola kirilowi (RKW) or $50 \%$ hydro-alcoholic (RKW-A) extracts, administered to pregnant and lactating mice, on the immune system of the resulting six-week old progeny. This experimental model is used by the present study to evaluate whether the use of $R$. kirilowii extract as an immunostimulant in pregnancy is safe for the developing immune system of the progeny (14). 


\section{Materials and methods}

Plant cultivation. R. kirilowii roots and rhizomes were cultivated, identified and collected in the Research Institute of Medicinal Plants, now the Institute of Natural Fibers and Medicinal Plants (Poznań, Poland). The voucher specimen was kept in the herbarium of Department of Botany, Breeding and Agriculture (Plewiska, Poland).

Preparation and chemical analysis of extracts. Extracts were prepared as previously described (12). Briefly, to produce RKW extract, finely powdered $R$. kirilowii roots were extracted twice with water (first for $2 \mathrm{~h}$ and then for $1 \mathrm{~h}$ ) in a raw material: Solvent ratio of $1: 5$, at between 40 and $45^{\circ} \mathrm{C}$ by the water extraction method. Resulting supernatants were mixed together, centrifuged (15 $\mathrm{min}$, room temperature, 2000 x $g$ ) and lyophilized. To produce RKW-A extract: Finely powdered $R$. kirilowii roots were extracted with a 1:1 ethanol: Water solution, in a raw material: Solvent ratio of 1:10 using the percolation method. Then, percolates were lyophilized following distillation at between 40 and $45^{\circ} \mathrm{C}$. Dry extract ratio were 5.09:1 for RKW and 3.27:1 for RKW-A. Extracts were stored at $-70^{\circ} \mathrm{C}$ until required.

Chemical analysis of extracts. Chemical analysis of extracts was performed as previously described (15), according to the methods proposed by Hertog et al (16). Briefly, the polyphenol concentration of the extracts was assayed using high-performance liquid chromatography (HPLC; Dionex system, pump P680, autosampler ASI100; Thermo Fisher Scientific, Inc., Waltham, MA, USA) equipped with a CoulArray Coloumetric Array Electrochemical Detector (ECD; Thermo Fisher Scientific, Inc.).

Experimental animals. Experiments were performed on 202 6-week old progeny ( 80 from control, 59 from RKW and 63 from RKW-A mothers) of 70 adult inbred female BALB/c mice (8-9 weeks old; 20 g; Mossakowski Medical Research Centre Polish Academy of Sciences, Warsaw, Poland), which were mated with adult males of the same strain. Between the appearance of a copulatory plug and 28 days following delivery, females were fed daily with lyophilized RKW $(n=20)$ or RKW-A ( $\mathrm{n}=19)$ extract. The extracts were given at a dosage of $20 \mathrm{mg} / \mathrm{kg}\left(7 \mathrm{mg} / \mathrm{m}^{2}\right)$, to mice weighing $20 \mathrm{~g}$ with a body surface area of $0.007 \mathrm{~m}^{2}$, which corresponds to a dose of $100 \mathrm{mg}(1.6 \mathrm{mg} / \mathrm{kg})$ given to a person weighing $60 \mathrm{~kg}$ with a body surface area of $1.6 \mathrm{~m}^{2}(1.6 \mathrm{mg} / \mathrm{kg})(17)$. The control group $(n=31)$ received distilled water instead of extract. The substances given were applied on a corn crisp and served to the mice in a Petri dish.

Experimental animals were handled in accordance with the Polish regulations concerning the wellness of laboratory animals (Polish National Institute of Health, Warsaw, Poland). All experiments were accepted by and conducted in accordance with the ethical guidelines of the Local Ethics Committee (IV) on Animal Testing, National Medicines Institute, Warsaw, Poland (permission no. 73/2011). Mice were maintained under typical conditions $\left(22.5-23.0^{\circ} \mathrm{C}\right.$, relative humidity $50-70 \%$, $12 \mathrm{~h}$ day/night cycle) with ad libitum access to breeding rodent feed (Labofeed H; Factory of Fodder, Kcynia, Poland) and water. Female and male progeny were housed separately. Pups were withdrawn from mothers 24 days following delivery.

Sera and spleen isolation. Mice were retro-orbitally bled under anesthesia [intraperitoneal injection of ketamine $(120 \mathrm{mg} / \mathrm{kg})$ and xylazine (12 mg/kg); Polypharm S.A., Warsaw, Poland]. Serum was separated by clotting for $1 \mathrm{~h}$ at room temperature, followed by centrifugation at $2000 \times \mathrm{g}$ for $20 \mathrm{~min}$ at $4^{\circ} \mathrm{C}$ and then stored at $-70^{\circ} \mathrm{C}$ until required. Following bleeding, mice were sacrificed by anesthetic overdose (pentobarbital, $400 \mathrm{mg} / \mathrm{kg}$; Polypharm S.A, Warsaw, Poland) and spleens were isolated under aseptic conditions (laminar flow cabinet), for immediate use.

Morphometric evaluation of spleens. Histological evaluation and quantitative microscopic analysis of lymphatic nodules was performed on hematoxylin and eosin stained paraffin sections of the spleens obtained from the progeny ( $n=10$ from each group). The histotechnical criteria applied for quantitative analysis were as follows: i) A thickness of between 3 and $5 \mu \mathrm{m}$; ii) complete transversal section of the spleen including white and red pulp structures; and iii) no evidence of traumatic artifacts within the sample, such as fragmentation or hemorrhage. The diameter of splenic nodules and the number of lymphatic nodules per microscopic field were measured. The surface of the section of spleen was then analyzed in regards to the following: i) The total area and number of white pulp lymphatic nodules, with the results expressed as the number per microscopic field $\left(5.5 \mathrm{~mm}^{2}\right)$; and ii) lymphatic nodule diameters measured in consecutive nodules. Images were acquired and processed using ToupView software (version 3.7; ToupTek Photonics Co., Ltd., Hangzhou, China).

Light microscopy examination, using an Evolution 100 Trino optical microscope (Delta Optical; Mińsk Mazowiecki, Poland) connected to a photometric color CCD camera (UCMOS05100KPA; Hangzhou ToupTek Photonics Co., Ltd.), of the red and white pulp (sites of hematopoiesis) was performed. In the red pulp attention was paid to splenic cords and venous sinuses. In the white pulp, the follicles, germinal centers, periarteriolar lymphoid sheath (PALS) and marginal zone were assessed. Fixed spleen preparations were examined using a panchromatic lens (numerical aperture, 0.25) at x100 magnification.

Preparation of splenocyte suspension. Spleens were gently pressed through a sterile nylon strainer $(40 \mu \mathrm{m})$ into a $50 \mathrm{ml}$ Flacon tube with $20 \mathrm{ml}$ of culture medium [Roswell Park Memorial Institute (RPMI)-1640 medium with GlutaMAX; Thermo Fisher Scientific, Inc., Warsaw, Poland], supplemented with $10 \%$ fetal bovine serum (FBS; Thermo Fisher Scientific, Inc., Warsaw, Poland) and antibiotics (50 IU/ml penicillin; $50 \mu \mathrm{g} / \mathrm{ml}$ streptomycin; Thermo Fisher Scientific, Inc.). Strainers were rinsed twice with media to remove remaining cells. Then, cells were centrifuged (500 x $g, 5 \mathrm{~min}$, room temperature), the resulting pellet resuspended in media and cells counted in a hematological analyzer (Exigo veterinary hematological system; Boule Medical AB, Stockholm, Sweden). A cell suspension of $1 \times 10^{6}$ cells $/ \mathrm{ml}$ was used to evaluate response to mitogens. Splenocyte viability was determined using the trypan blue exclusion test and amounted 
to $>95 \%$ cell viability. Following preparation, cells were immediately used.

Phenotypic determination of splenocytes. Spleen cell suspensions $\left(1 \times 10^{6} \mathrm{cell} / \mathrm{ml}\right)$ were washed twice with phosphate buffered saline (PBS) and centrifuged (500 x $g, 5 \mathrm{~min}$, room temperature). Cell pellets were resuspended in $1 \mathrm{ml}$ of PBS and $100 \mu 1$ of the suspension was labeled by cell-surface marker staining with the following fluorochrome-coniugated anti-mouse monoclonal antibodies: Mouse $\mathrm{T}$ lymphocyte Subset Antibody Cocktail with Isotype Control [hamster anti-mouse phycoerythrin (PE)-Cyanine 7 cluster of differentiation (CD) 3e, rat anti-mouse PE CD4 and rat anti-mouse allophycocyanin (APC) CD8a; cat. no 558431; ready-to-use], Mouse B Lymphocyte Activation Antibody Cocktail with Isotype Control (rat anti-mouse PE-Cy7 CD25, hamster anti-mouse PE CD69 and rat anti-mouse APC CD19; BD Biosciences, Warsaw, Poland; cat. no. 558063; ready-to-use) and PE rat anti-mouse CD335 (natural killer cell p46-related protein; cat. no. 560757) (all BD Biosciences, Warsaw, Poland), according to the manufacturer's instructions (20 min incubation at room temperature). Red blood cells from splenocyte suspensions were lysed (10 min, Lysing Solution 10X Concentrate; BD Biosciences). Phenotypic analysis was then performed using flow cytometry (FACSCalibur; BD Biosciences). Results of this analysis are presented as the mean $\%$ of splenocytes of a particular phenotype \pm the standard error of the mean.

Response of splenocytes to mitogens. Response to mitogens was measured using two tests; the alamarBlue assay and $\left[{ }^{3} \mathrm{H}\right]$ thymidine incorporation assay. For the alamarBlue assay, splenocytes were seeded into 96 -well plates $\left(1 \times 10^{5}\right.$ cell/well), incubated for $1 \mathrm{~h}$ under standard condition $\left(5 \% \mathrm{CO}_{2}, 95 \%\right.$ humidity, $37^{\circ} \mathrm{C}$ ) and then a mitogen was added to each well: Lipopolysaccharide (LPS; $20 \mu \mathrm{g} / \mathrm{ml}$ ), Concanavalin A (ConA; $5 \mu \mathrm{g} / \mathrm{ml}$ ) or phytohaemagglutinin (PHA; $2 \mu \mathrm{g} / \mathrm{ml}$ ) (all purchased from Sigma-Aldrich, Poznań, Poland). Following 24 h of incubation, alamarBlue (1:10, v/v; Thermo Fisher Scientific, Inc., Warsaw, Poland) was added to the wells. Cells were incubated for $24 \mathrm{~h}$ at standard conditions $\left(37^{\circ} \mathrm{C}, 5 \% \mathrm{CO}_{2}, 95 \%\right.$ relative humidity). Then, alamarBlue fluorescence (excitation $544 \mathrm{~nm}$, emission $590 \mathrm{~nm}$ ) of the wells was measured using a FLUOstar Omega Microplate Reader (BMG Labtech GmbH, Ortenberg, Germany) as previously described (18). For the $\left[{ }^{3} \mathrm{H}\right]$ thymidine incorporation assay (19), cells were cultured and treated with mitogens as described above. Then, the cultures were incubated for $48 \mathrm{~h}$ prior to being pulsed with thymidine $\left({ }^{3} \mathrm{HTdR}\right.$, $2 \mathrm{Ci} / \mathrm{mM}, 0,4 \mu \mathrm{C} / 20 \mu \mathrm{l} /$ culture) and cultured for a further $24 \mathrm{~h}$. Following culture, cells were transferred onto Whatman filter paper discs (Labo Plus, Warsaw Poland), extracted with $30 \%$ trichloroacetic acid, dehydrated using alcohol and ether, and transferred to glass scintillation vessels filled with liquid scintillation mixture (cat no: 327123; Sigma-Aldrich; Thermo Fisher Scientific, Inc.). The measurements were taken using a Packard Tri-Carb 2100TR scintillation counter (PerkinElmer, Inc., Waltham, MA, USA). Tests were performed in triplicate and an unstimulated control was included.

Cytokine determination. Flow cytometry determination of the concentration of selected cytokines [interleukin (IL)-2, -4, -6,
-10 and $-17 \mathrm{~A}$, tumor necrosis factor- $\alpha$ (TNF- $\alpha$ ) and interferon- $\gamma$ (IFN- $\gamma$ )] in the sera was evaluated using the Mouse Th1/ Th2/Th17 Cytokine Kit (cat. no. 560485, BD Biosciences), according to the manufacturer's protocol.

Anti-sheep red blood cell (SRBC) CD2 antibody production. Progeny mice (6-weeks old) were immunized with 5\% SRBC $(0.2 \mathrm{ml}$ intraperitoneal injection; Graso Biotech, Gdański, Poland) 7 days prior to being bled under anesthesia from the retro-orbital plexus. Anti-SRBC antibody levels were evaluated by performing a hemagglutination assay, as previously described (20), on a series sera dilutions. Briefly, following heat inactivation of the sera $\left(56^{\circ} \mathrm{C}, 30 \mathrm{~min}\right), 1 \% \mathrm{SRBC}$ was added and the mixture was incubated for $60 \mathrm{~min}$ at $37^{\circ} \mathrm{C}$, incubated for $18 \mathrm{~h}$ at $4^{\circ} \mathrm{C}$, and centrifuged $(10 \mathrm{~min}, 150 \mathrm{x} \mathrm{g}$, $4^{\circ} \mathrm{C}$ ) and shaken. The hemagglutination titer was defined, using light microscopy, as the highest dilution in which $\geq 3$ cell conglomerates were present in $\geq 3$ consecutive fields at an objective magnification of $\mathrm{x} 20$. For the purposes of statistical analysis, results were transformed into logarithm inversions of the titers.

Statistical analysis. Statistical evaluation of the results obtained, from the control and experimental groups, was performed using unpaired $t$-tests and one- or two-way analysis of the variance, followed by the Tukey test or Bonferroni correction (in the case of a normal distribution) or non-parametric Kruskal-Wallis and Mann-Whitney U tests (in the case of abnormal distribution). Assessment of the distribution of the data was evaluated using the Shapiro-Wilk test. GraphPad Prism software was used to carry out these tests (version 5; GraphPad Software, Inc., La Jolla, CA, USA). P $<0.05$ was considered to indicate a statistically significant difference.

\section{Results}

Chemical analysis of extracts. RKW and RKW-A extracts were found to contain phenyloethanoid salidroside and thyrozol, four phenolic acids (chlorogenic, ferulic, ellagic and p-coumaric), and flavonoids [fisetin, naringenin, kaempferol, epicatechin, luteolin, quercetin, epigallocatechin and (+)-catechin]. HPLC-ECD analysis revealed a significant difference in the content of biologically active compounds between RKW and RKW-A extracts $(\mathrm{P}<0.0001)$. Typically, RKW-A extract presented a higher concentration of the identified compounds than RKW. The total concentration of polyphenols amounted to $16.16 \mu \mathrm{g} / \mathrm{mg}$ in RKW and $23.75 \mu \mathrm{g} / \mathrm{mg}$ in RKW-A.

Spleen morphology. No macroscopic abnormalities were identified in the anatomy of spleens from the experimental and control groups. Similarly, no differences in the relative weight, cellularity (Fig. 1) and morphological picture of spleens were observed between the groups. Splenic lymphatic nodules were large, with well-developed germinal centers. In addition, the PALS and marginal zone were found to be normal in all groups. The red pulp of the spleen was moderately plethoric. Morphometric evaluation did not reveal differences between the experimental and control groups in regards to the number of lymphatic nodules per microscopic field and their diameter (Table I). 
Table I. Morphometric analysis of the spleen in control and experimental animals.

\begin{tabular}{lcccc}
\hline Group & $\begin{array}{c}\text { Number of } \\
\text { images analyzed }\end{array}$ & $\begin{array}{c}\text { Number of lymphatic } \\
\text { nodules/field } \pm \text { SEM }\end{array}$ & $\begin{array}{c}\text { Number of lymphatic } \\
\text { nodules analyzed }\end{array}$ & $\begin{array}{c}\text { Mean diameter of } \\
\text { nodule (mm) } \pm \text { SEM }\end{array}$ \\
\hline Control & 34 & $9.23 \pm 0.49$ & 316 & $0.323 \pm 0.0074$ \\
RKW & 41 & $10.34 \pm 0.52$ & 414 & $0.318 \pm 0.0059$ \\
RKW-A & 32 & $9.62 \pm 0.59$ & 308 & $0.334 \pm 0.0062$ \\
\hline
\end{tabular}

No significant differences were found (statistical analysis: Shapiro-Wilk normality test, one-way analysis of the variance, Tukey comparison test; $\alpha=0.05)$. RKW, Rhodiola kirilowii water extract; RKW-A, Rhodiola kirilowii hydro-alcoholic extract; SEM, standard error of the mean.

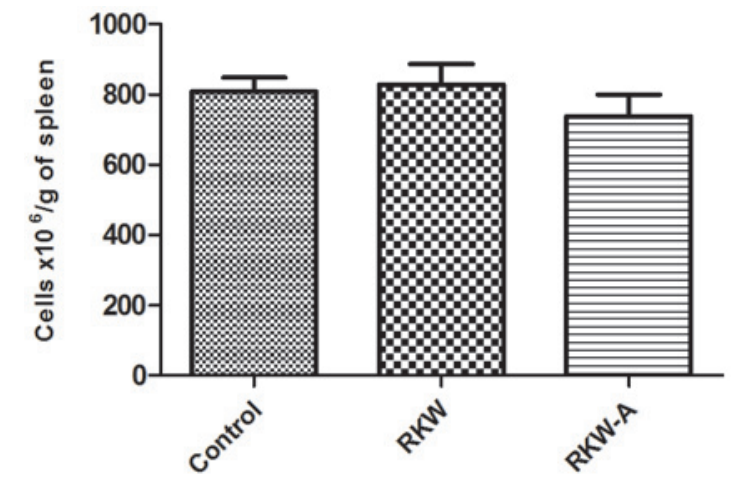

Figure 1. Cellularity of progeny spleens. Results presented are the mean of cells calculated per gram of spleen \pm standard error of the mean. Number of spleens tested, 87 (control, 41; RKW, 24; RKW-A, 22). RKW, Rhodiola kirilowii water extract; RKW-A, Rhodiola kirilowii hydro-alcoholic extract.

Phenotype of splenocytes. The percentage of $\mathrm{CD}^{+}$cells was highest in spleens collected from the progeny of mice fed RKW extract during pregnancy, and amounted to $63 \%$ of all $\mathrm{CD}^{+}{ }^{+}$splenocytes from the group. In comparison, in splenocytes from the progeny of RKW-A extract-fed mothers and control mothers, corresponding values were 52 and $55 \%$, respectively. The $\mathrm{CD}^{+}: \mathrm{CD}^{+}$ratio was $2.35 \pm 0.2$ in the RKW group, in comparison to $1.88 \pm 0.1$ in the RKW-A group and $2.41 \pm 0.2$ in the control group. The results described are presented in Fig. 2.

Splenocytic response to mitogens. The alamarBlue assay identified that offspring of mice fed with RKW extract during pregnancy and lactation showed a significantly higher level of metabolic activity following addition of the mitogen PHA compared with the offspring of mice fed with RKW-A $(\mathrm{P}=0.0496)$, which did not affect metabolic activity and slightly decreased proliferation following PHA stimulation (Fig. 3A). However, no significant differences between groups in response to PHA were found by the $\left[{ }^{3} \mathrm{H}\right]$ thymidine incorporation assay (Fig. 3B). In cells from ConA-stimulated spleens the alamarBlue assay found no differences in proliferation between the study and control groups in ConA stimulated cells (control, $156 \pm 3.9, \mathrm{n}=31$; RKW, 153 $\pm 5.2, \mathrm{n}=16$; RKW-A, 151 \pm 4.5 , $\mathrm{n}=12$ ) (Fig. 4A), while the $\left[{ }^{3} \mathrm{H}\right]$ thymidine incorporation assay identified significantly lower $\left[{ }^{3} \mathrm{H}\right]$ thymidine incorporation in cells collected from experimental groups in comparison to the control (RKW, P=0.0306; RKW-A, P=0.0356; Fig. 4B).

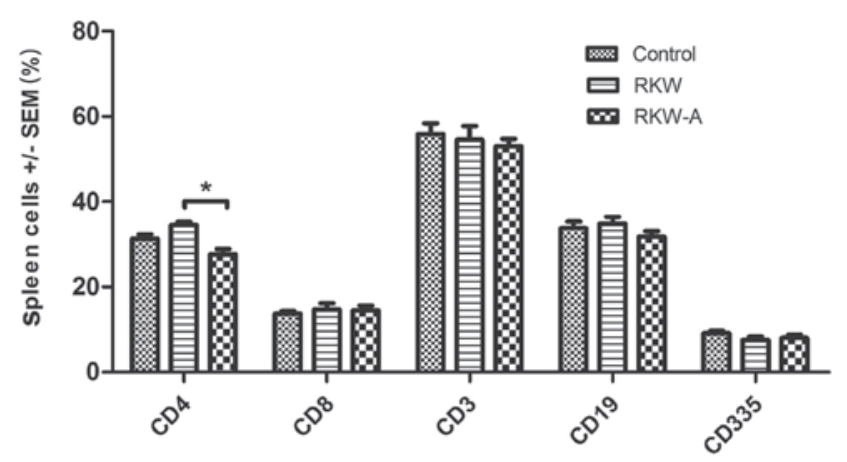

Figure 2. Phenotypes of spleen lymphocytes. Phenotypic analysis was performed by flow cytometry [number of spleens tested, 46 (control, 15; RKW, 13; RKW-A, 18)]. Results are presented as the mean percentage of spleen cells \pm SEM. Statistical analysis performed: Unpaired $t$-test, Shapiro-Wilk normality test, two-way analysis of the variance and Bonferroni correction. SEM, standard error of the mean; CD, cluster of differentiation; RKW, Rhodiola kirilowii water extract; RKW-A, Rhodiola kirilowii hydro-alcoholic extract. * $\mathrm{P}=0.0004$.

In LPS-stimulated cells the alamarBlue assays found no significant difference between groups (Fig. 5A), while the $\left[{ }^{3} \mathrm{H}\right]$ thymidine incorporation assays found significantly lower cell proliferation in the RKW-A group compared with the control $(\mathrm{P}=0.0175$; Fig. 5B).

Cytokine concentrations in mice sera. The serum concentrations of selected cytokines (IL-2, -4, -6, -10 and $-17 \mathrm{a}, \mathrm{TNF}-\alpha$, and IFN- $\gamma$ ) were evaluated by flow cytometry. No statistically significant differences were found in the serum concentrations of IL $-2,-4$ and -6 , and IFN- $\gamma$ between groups (Fig. 6A-D). The serum concentration of TNF- $\alpha$ was significantly higher in the RKW-A group compared with the control ( $\mathrm{P}=0.0123$; Fig. 6E). Serum IL-17a concentration was significantly lower in mice whose mothers were fed during pregnancy and lactation with RKW extract compared with the control ( $\mathrm{P}=0.0347$; Fig. 7A). However, there were no differences between mice of RKW-A and control mothers (Fig. 7A). In addition, IL-10 serum concentration was higher $(\mathrm{P}=0.0581)$ in the RKW-A group compared with the control (Fig. 7B).

Anti-SRBC antibody production. The mean of log titer of anti-SRBC antibody production was significantly lower in progeny of mice fed RKW-A extract $(\mathrm{P}=0.0305)$ compared with those of mice fed water (Fig. 8). There was no difference 
A

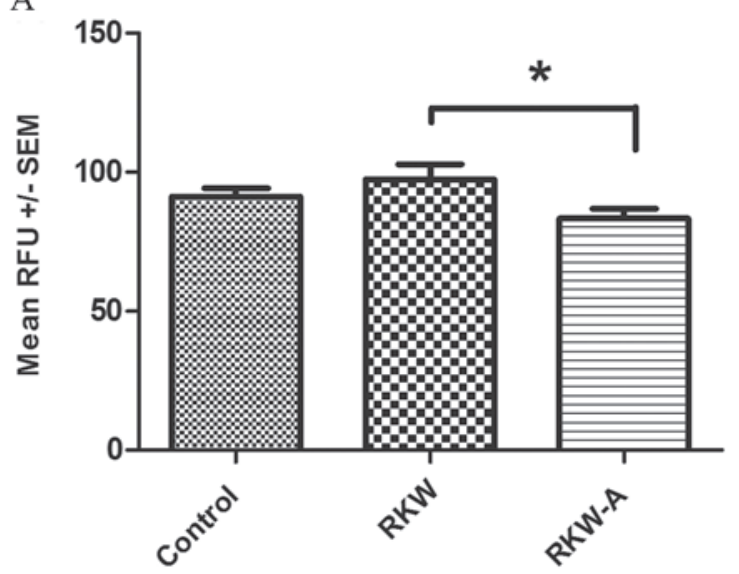

B

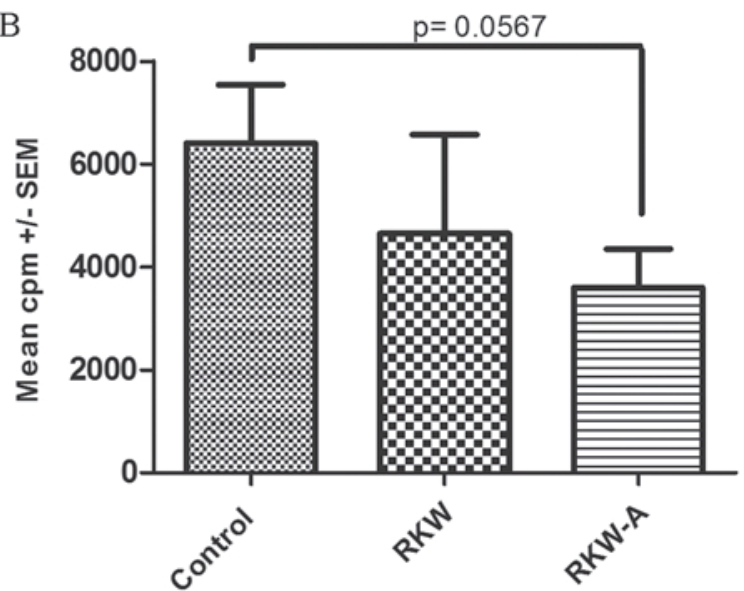

Figure 3. Proliferation index of splenocytes following phytohemagglutinin (PHA) stimulation. Results are presented as the mean RFU or cpm \pm SEM, measured by the (A) alamarBlue assay [number of spleens tested, 59 (control, 31; RKW, 16; RKW-A, 12)] or (B) $\left[{ }^{3} \mathrm{H}\right]$ thymidine incorporation assay following PHA $(2 \mu \mathrm{g} / \mathrm{ml})$ stimulation [number of spleens tested, 27 (control, 9; RKW, 9; RKW-A, 9)]. Statistical analysis performed: Unpaired $t$-test, Shapiro-Wilk normality test, one-way analysis of the variance and the Tukey comparison test. RFU, relative fluorescence units; SEM, standard error of the mean; cpm, counts per minute; RKW, Rhodiola kirilowii water extract; RKW-A, Rhodiola kirilowii hydro-alcoholic extract. " $\mathrm{P}=0.0496$.

A

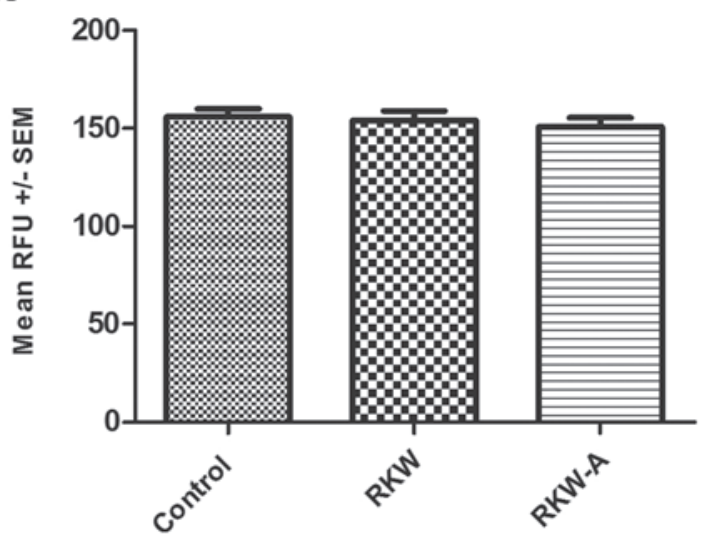

B

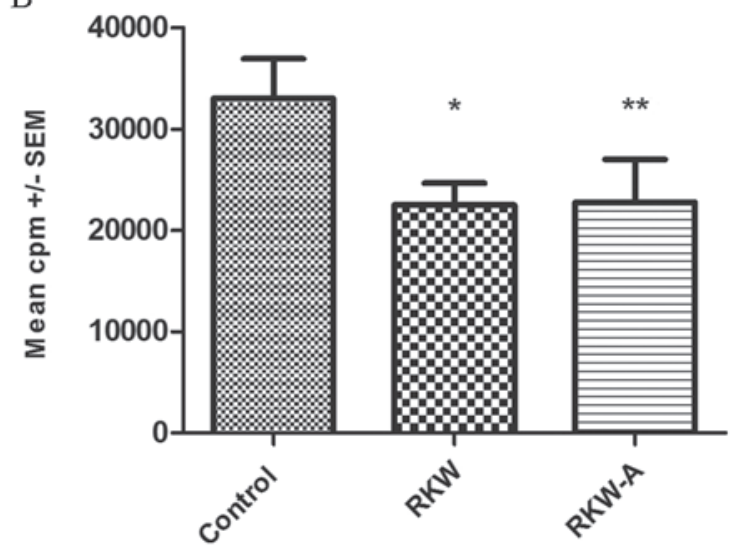

Figure 4. Proliferation indexes of splenocytes following Concanavalin A (ConA) stimulation. Results are presented as the mean RFU or cpm \pm SEM, measured by the (A) alamarBlue assay [number of spleens tested, 59 (control, 31; RKW, 16; RKW-A, 12)] or (B) [ $\left.{ }^{3} \mathrm{H}\right]$ thymidine incorporation assay following ConA $(5 \mu \mathrm{g} / \mathrm{ml})$ stimulation [number of spleens tested, 27 (control, 9; RKW, 9; RKW-A, 9)]. Statistical analysis performed: Unpaired $t$-test, Shapiro-Wilk normality test, one-way analysis of the variance and the Tukey comparison test. RFU, relative fluorescence units; SEM, standard error of the mean; cpm, counts per minute; RKW, Rhodiola kirilowii water extract; RKW-A, Rhodiola kirilowii hydro-alcoholic extract. ${ }^{*} \mathrm{P}=0.0306$ vs. control; ${ }^{* *} \mathrm{P}=0.0356$ vs. control.

between progeny of mice fed with RKW and those of mice fed water control (Fig. 8).

\section{Discussion}

To best of our knowledge, the present study is the first to investigate the influence of $R$. kirilowii extract, administered to pregnant and lactating mice, on the immune system of their progeny. The immune system is crucial for the survival of complex organisms, such as mice and humans, because of its function in defense against diseases and in regulation of homeostasis. The primary cells of the immune system are lymphocytes, therefore, the present study investigated their proliferative activity and expression of cytokines.

The results of the present study determined that the spleen lymphocytes of mice whose mothers were fed during pregnancy and lactation with RKW extract were more able to metabolize resazurin when stimulated with PHA, compared with splenocytes from mice whose mothers were fed RKW-A extract. Differences in the results obtained from the alamarBlue and $\left[{ }^{3} \mathrm{H}\right]$ thymidine incorporation assays are a result of the test specificity. Tge alamarBlue assay measures the metabolic activity of the cells, whereas $\left[{ }^{3} \mathrm{H}\right]$ thymidine incorporation is based on de novo DNA synthesis during proliferation.

Lymphocyte activation is usually typically associated with the expression of IL-2, $-4,-6,-10$ and -17 , and TNF- $\alpha,(21,22)$. IL-2 promotes proliferation of and cytokine production by T-cells, and serves an important role in the maintenance of the functional properties of B cells (23). IL-4 is a key regulator of the immune response and promotes the differentiation of naive T cells into T helper (Th) 2 cells (24). IL-6 has been shown to influence inflammatory action and the antigen-specific immune response (25). In addition, IL-6 serves an important role in cellular defense mechanisms trough regulating hema- 
A

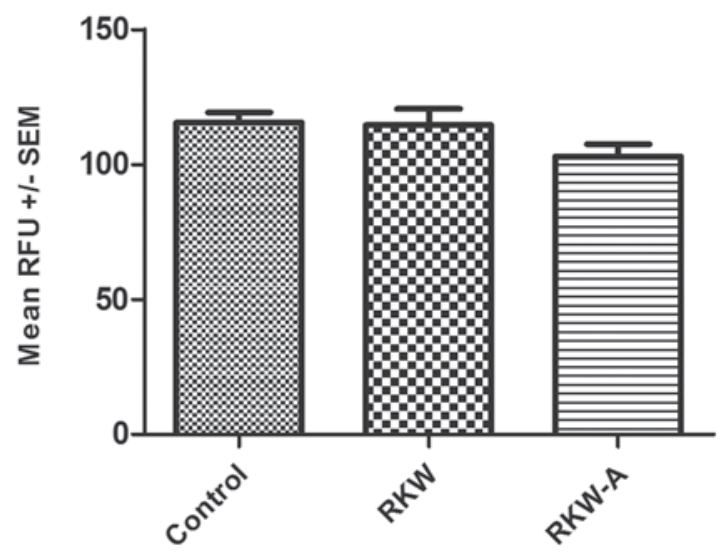

B

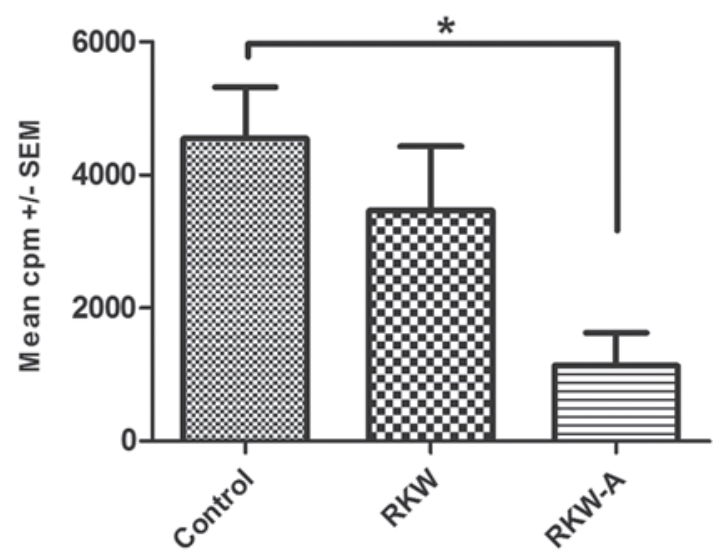

Figure 5. Proliferation index of splenocytes following lipopolysaccharide (LPS) stimulation. Results are presented as the mean RFU or cpm \pm SEM, measured by the (A) alamarBlue assay [number of spleens tested, 59 (control, 31; RKW, 16; RKW-A, 12)] or (B) [ $\left.{ }^{3} \mathrm{H}\right]$ thymidine incorporation assay following LPS $(20 \mu \mathrm{g} / \mathrm{ml})$ stimulation [number of spleens, 27 (control, 9; RKW, 9; RKW-A, 9)]. Statistical analysis performed: Unpaired $t$-test, Shapiro-Wilk normality test, one-way analysis of the variance and the Tukey comparison test. RFU, relative fluorescence units; SEM, standard error of the mean; cpm, counts per minute; RKW, Rhodiola kirilowii water extract; RKW-A, Rhodiola kirilowii hydro-alcoholic extract. " $\mathrm{P}=0.0175$.

A

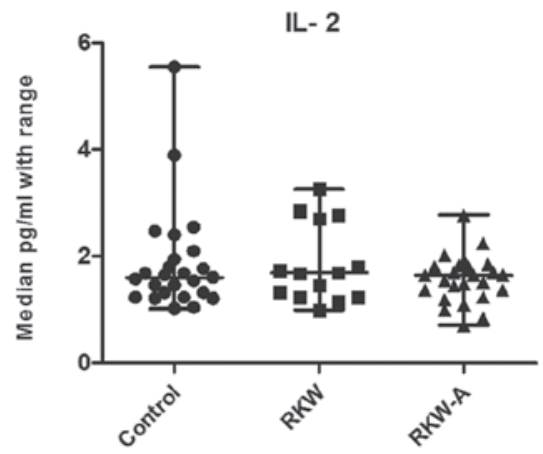

$\mathrm{D}$

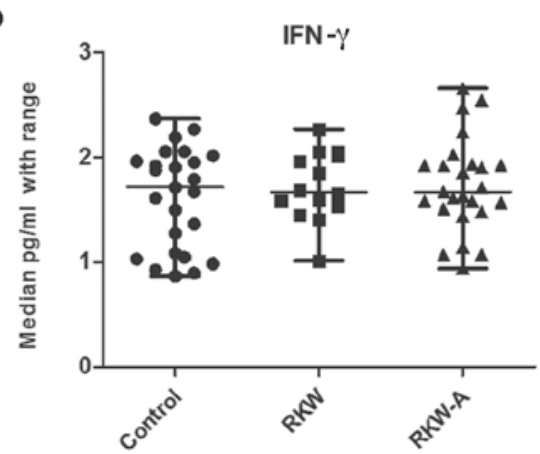

B

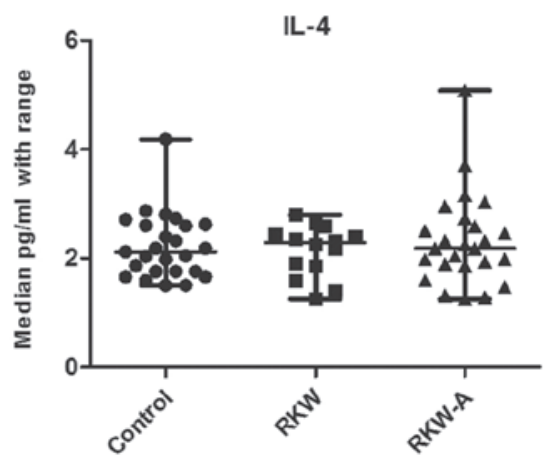

$\mathrm{E}$

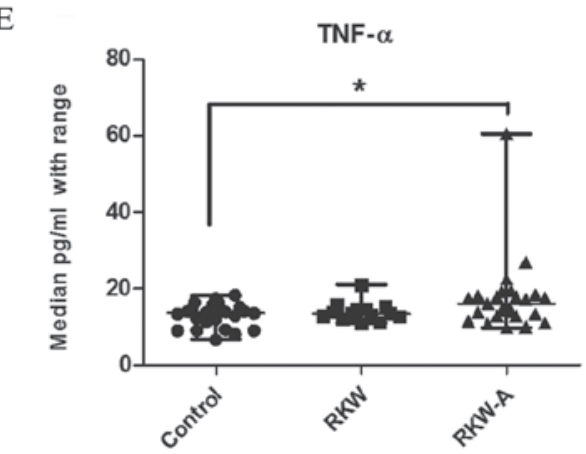

Figure 6. Concentration of selected cytokines (A) IL-2, (B) IL-4, (C) IL-6, (D) IFN- $\gamma$ and (E) TNF- $\alpha$ in the sera. $n=54$ mice (control, 20; RKW, 18; RKW-A, 16). Results presented are the median \pm the range of the cytokine in $\mathrm{pg} / \mathrm{ml}$. Statistical analysis performed: Unpaired $t$-test, Shapiro-Wilk normality test, Kruskal-Wallis test and Dunn's test. RKW, Rhodiola kirilowii water extract; RKW-A, Rhodiola kirilowii hydro-alcoholic extract. "P=0.0123 from Mann Whitney test.

topoiesis and the immune response (26). Primarily produced by Th2 lymphocytes, IL-10 generates and promotes $\mathrm{T}$ cell tolerance, via downregulation of IFN- $\gamma$, IL-2 and -5 production, proinflammatory cytokines, and eosinophil function and activity (27). TNF- $\alpha$ functions in the initiation of cellular and humoral immune responses (28).

In the present study, a minor increase was observed in the production of immunoregulatory IL-10 in mice whose mothers were fed with RKW-A extract, with a simultaneous increase in sera TNF- $\alpha$ concentration. This may be the reason for the altered spleen cell metabolism observed earlier, confirming the results of the alamarBlue and $\left[{ }^{3} \mathrm{H}\right]$ thymidine incorporation assays. TNF- $\alpha$ directly promotes the growth and differentiation of neutrophils, macrophages and B cells.

IFN- $\gamma$, synthesized by natural killer cells and Tymphocytes, serves a role in the immune response against pathogens. IFN $-\gamma$ activates macrophages and promotes differentiation of $\mathrm{CD}^{+} \mathrm{T}$ lymphocytes into Th1 cells. However, in the present study this was not the case, because there were no differences in sera IFN- $\gamma$ concentrations between the progeny of mice 
A

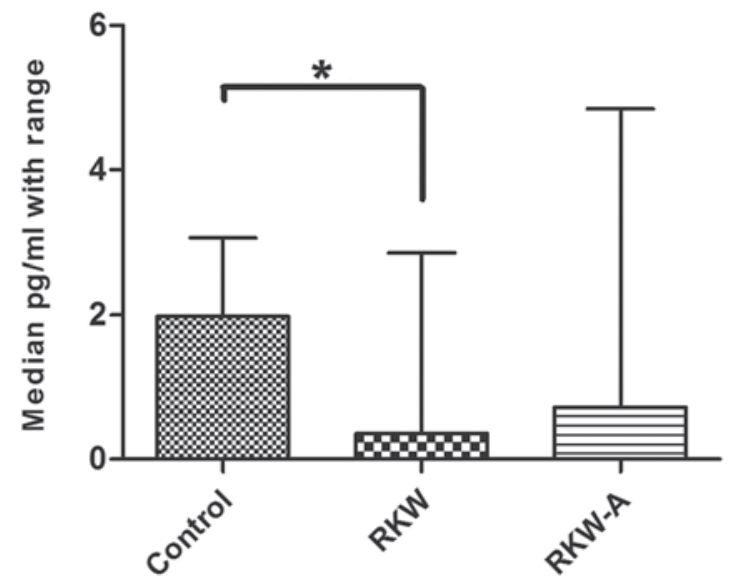

B

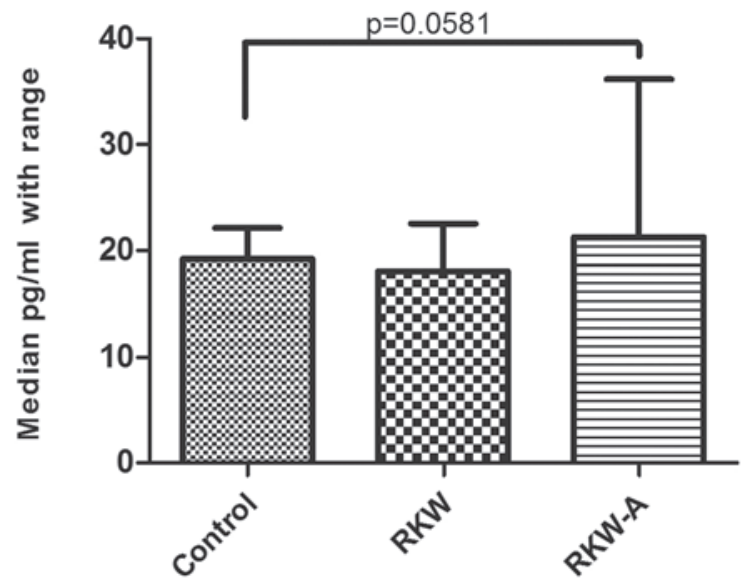

Figure 7. Concentration of (A) IL-17a and (B) IL-10 cytokines in the sera. $n=54$ mice (control, 20; RKW, 18; RKW-A, 16). Results present the median \pm the range of the cytokine in $\mathrm{pg} / \mathrm{ml}$. Statistical analysis performed: Unpaired $t$-test, Shapiro-Wilk normality test and the Kruskal-Wallis test. RKW, Rhodiola kirilowii water extract; RKW-A, Rhodiola kirilowii hydro-alcoholic extract. " $\mathrm{P}=0.0347$.

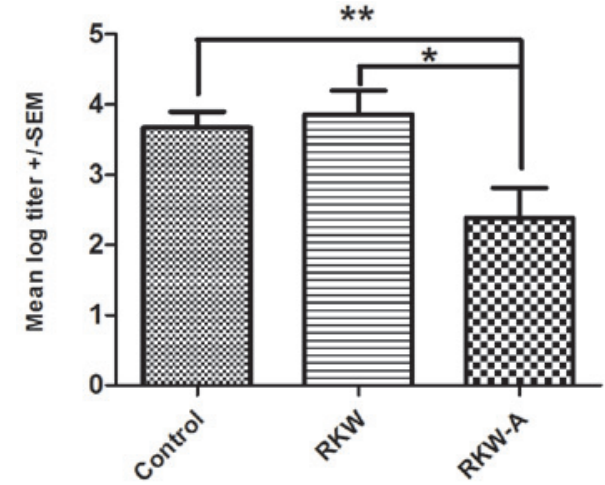

Figure 8. Levels of anti-sheep red blood cell (SRBC) antibody production. Results are presented as the mean log titer \pm SEM of anti-SRBC antibody production in progeny whose mothers were fed RKW and RKW-A extracts during pregnancy and lactation. $\mathrm{n}=29$ mice (control, 9; RKW, 7; RKW-A, 13). Statistical analysis performed: Unpaired $t$-test, Shapiro-Wilk normality test, one-way analysis of the variance and the Tukey comparison test. SEM, standard error of the mean; RKW, Rhodiola kirilowii water extract; RKW-A, Rhodiola kirilowii hydro-alcoholic extract. ${ }^{*} \mathrm{P}=0.0331,{ }^{* * *} \mathrm{P}=0.0305$.

fed Rhodiola extracts and the progeny of mice fed water (control).

Th17 cells primarily produce IL-17a, which is important in inducing and mediating the proinflammatory responses. In addition, IL-17a induces and promotes the production of the cytokines IL-6, TNF- $\alpha$, granulocyte-colony stimulating factor, granulocyte-macrophage colony-stimulating factor, IL-1 $\beta$, TGF- $\beta$ cytokines and the chemokines IL-8, growth related oncogene-a and monocyte chemoattractant protein-1 $(29,30)$. A previous study found that IL-17a can down-regulate Th1 differentiation (31).

The present study identified that RKW and RKW-A extracts did not change progeny sera expression of IFN- $\gamma$, IL-2, -4 or -6 compared with the control. However, TNF- $\alpha$ and IL-10 expression were increased in the progeny of mice fed with RKW-A extract. In addition, mice whose mothers were fed with RKW-A had lower antibody titers following immunization with SRBC, which may be connected with the increased serum concentration of IL-10 and decreased splenocyte response to LPS (a B cell mitogen) identified in the current study.

Interestingly, a significantly lower concentration of IL-17a in the sera and a significantly higher metabolic response to PHA was observed in the splenocytes of mice born to RKW-fed mothers, compared with mice born to mothers fed with RKW-A. This is consistent with the results of a previous study in a mouse model of acute graft-vs.-host disease, in which the authors determined that the absence of Th17 cells lead to augmented Th1 differentiation (31). These results suggest that PHA-responsive spleen cells are T helper lymphocytes, members of the Th1 population.

A previous study (14), in addition to the present study, observed a higher number of pups in the litters delivered by mothers that were fed RKW-A extracts. This is in agreement with a number of pre-clinical and clinical observations on the beneficial reproductive effects of other Rhodiola species, such as $R$. rosea $(32,33)$.

Antibody production by B-cells is the primary component of the adaptive immunity response. Disorders in antibody production impair the ability of an organism to defend against microbial infections. In the present study, administration of RKW-A extract to mothers significantly decreased SRBC antibody production in comparison with RKW extract and the control (water). A previous study found water and hydro-alcoholic extracts of $R$. quadrifida had no effect on anti- SRBC antibody production (34). In contrast, Mishra et al reported that $R$. imbricata aqueous extract significantly enhanced tetanus toxoid-specific immunoglobulin levels and ovalbumin-induced antibody responses in a rat model (35). Differences in antibody production following supplementation of water or hydro-alcoholic extracts may be the result of the various Rhodiola species used in studies.

A recent study, performed in the same model, found that thymuses obtained from the progeny of mice treated with both types of $R$. kirilowii extract showed significantly lower total 
apoptotic cell counts compared with the progeny of control mice, and that such treatment of mothers had no significant influence upon IL-7 expression of progeny thymocytes (36). The study concluded that $R$. kirilowii extracts may help to preserve thymus function in the progeny of treated animals.

The question of what causes the differences in the observed effects of RKW and RKW-A extracts arose from the results of the present study. In the present study, analysis of the content of selected polyphenolic compounds in RKW and RKW-A showed quantitative differences only, for which there are two possible explanations. Firstly, RKW-A extract may contain substances other than the analyzed polyphenolic compounds, which in RKW are absent or present in very low concentrations. Secondly, the different influences of RKW and RKW-A extracts on developing fetuses may be a result of having different concentrations of the analyzed polyphenols. Thirdly, there may differences in the bioavailability and biodistribution of selected polyphenols in serum and milk of mice-mothers.

In conclusion, progeny of RKW-A mothers differ from the control and RKW offspring in lower antibody production, lower response of splenocytes to LPS and ConA, and higher serum concentrations of TNF- $\alpha$ and IL-10. Spleens of RKW progeny were found to contain more $\mathrm{CD} 4^{+}$cells compared with the spleens of control and RKW-A progeny. In addition, spleen cells collected from the progeny of RKW mice responded more to PHA (significantly in the almarBlue assay, on the borderline of significance in the $\left[{ }^{3} \mathrm{H}\right]$ thymidine incorporation assay) compared with corresponding cells from RKW-A progeny. However, RKW and RKW-A offspring splenocytes presented significantly lower responses to ConA in the $\left[{ }^{3} \mathrm{H}\right]$ thymidine incorporation assay compared with control group. Therefore, caution is recommended in the use of RKW and RKW- extracts, particularly long-term, as immunostimulants in pregnancy prior to further research.

\section{Acknowledgments}

The present study was supported by the National Centre of Science (Kraków, Poland; grant no. 2012/05/B/NZ 7/03219).

\section{References}

1. Zhang S, Gao W, Xu K, Guo Y, Lin S, Xue X, Lu G, Li N, Liu H and Liu W: Early use of Chinese drug rhodiola compound for patients with post-trauma and inflammation in prevention of ALI/ ARDS. Zhonghua Wai Ke Za Zhi 37: 238-240, 1999 (In Chinese).

2. Panossian A, Wikman G and Sarris J: Rosenroot (Rhodiola rosea): Traditional use, chemical composition, pharmacology and clinical efficacy. Phytomedicine 17: 481-493, 2010.

3. Hung SK, Perry R and Ernst E: The effectiveness and efficacy of Rhodiola rosea L.: A systematic review of randomized clinical trials. Phytomedicine 18: 235-244, 2011.

4. Mishra KP, Ganju L and Singh SB: Anti-cellular and immunomodulatory potential of aqueous extract of Rhodiola imbricata rhizome. Immunopharmacol Immunotoxicol 34: 513-518, 2012.

5. Chen SP, Huang Liu R, Lu TM, Wei JC, Wu TC, Tsai WY, Tsai CH and Yang CC: Complementary usage of Rhodiola crenulata (L.) in chronic obstructive pulmonary disease patients: The effects on cytokines and T cells. Phytother Res 29: 518-525, 2015.

6. Jeong HJ, Ryu YB, Park SJ, Kim JH, Kwon HJ, Kim JH, Park KH, Rho MC and Lee WS: Neuraminidase inhibitory activities of flavonols isolated from Rhodiola rosea roots and their in vitro anti-influenza viral activities. Bioorg Med Chem 17: 6816-6823, 2009.
7. Diwaker D, Mishra KP, Ganju L and Singh SB: Rhodiola inhibits dengue virus multiplication by inducing innate immune response genes RIG-I, MDA5 and ISG in human monocytes. Arch Virol 159: 1975-1986, 2014.

8. Ahmed M, Henson DA, Sanderson MC, Nieman DC, Zubeldia JM and Shanely RA: Rhodiola rosea exerts antiviral activity in athletes following a competitive marathon race. Front Nutr 2: 24, 2015.

9. Wang H, Ding Y, Zhou J, Sun X and Wang S: The in vitro and in vivo antiviral effects of salidroside from Rhodiola rosea $\mathrm{L}$. against coxsackievirus B3. Phytomedicine 16: 146-155, 2009.

10. Cybulska P, Thakur SD, Foster BC, Scott IM, Leduc RI, Arnason JT and Dillon JA: Extracts of Canadian first nations medicinal plants, used as natural products, inhibit neisseria gonorrhoeae isolates with different antibiotic resistance profiles. Sex Transm Dis 38: 667-671, 2011.

11. Furmanowa M, Skopińska-Różewska E, Rogala E and Hartwich M: Rhodiola rosea in vitro culture-phytochemical analysis and antioxidant action. Acta Societ Botanic Pol 67: 69-73, 1998.

12. Siwicki AK, Skopińska-Różewska E, Hartwich M, Wójcik R, Bakuła T, Furmanowa M, Bałan BJ, Sommer E, Mielcarek S, Buchwald W, et al: The influence of Rhodiola rosea extracts on non-specific and specific cellular immunity in pigs, rats and mice. Centr Eur J Immunol 32: 84-91, 2007.

13. Skopińska-Różewska E, Wójcik R, Siwicki AK, Sommer E, Wasiutýnski A, Furmanowa M, Malinowski $M$ and Mazurkiewicz M: The effect of Rhodiola quadrifida extracts on cellular immunity in mice and rats. Pol J Vet Sci 11: 105-111, 2008.

14. Zdanowski R, Lewicki S, Sikorska K, Żmigrodzka M, Buchwald W, Wilczak J and Skopińska-Różewska E: The influence of aqueous and hydro-alcoholic extracts of roots and rhizomes of Rhodiola kirilowii on the course of pregnancy in mice. Centr Eur J Immunol 39: 471-475, 2014.

15. Lewicki S, Stankiewicz W, Skopińska-Różewska E, Wilczak J, Leśniak M, Suska M, Siwicki AK, Skopiński P and Zdanowski R: Spleen content of selected polyphenols, splenocytes morphology and function in mice fed Rhodiola kirilowii extracts during pregnancy and lactation. Pol J Vet Sci 18: 847-855, 2015.

16. Hertog MGL, Hollman PCH and Venema DP: Optimization of a quantitative HPLC determination of potentially anticarcinogenic flavonoids in vegetables and fruits. J Agric Food Chem 40: 1591-1598, 1992.

17. Shin JW, Seol IC and Son CG: Interpretation of animal dose and human equivalent dose for drug development. J Korean Med 31: $1-7,2010$.

18. Zdanowski R, Stankiewicz W, Kamiński A, Grzela T, Skopiński P, Lewicki S and Skopińska-Rózewska E: The effect of sterilization by irradiation of human pericardium and skin frozen tissues on their ability to influence the proliferation of endothelial cells in vitro. Centr Eur J Immunol 37: 119-122, 2012.

19. Ahmed SA, Gogal RM Jr and Walsh JE: A new rapid and simple non-radioactive assay to monitor and determine the proliferation of lymphocytes: An alternative to [3H]thymidine incorporation assay. J Immunol Methods 170: 211-224, 1994.

20. Skopińska-Różewska E, Siwicki AK and Sommer E: Stimulation of humoral immunity in mice by some commercial fragrances. Centr Eur J Immunol 34: 232-234, 2009.

21. Alberts B, Johnson A, Lewis J, Raff M, Roberts K and Walter P: Helper $\mathrm{T}$ cells and lymphocyte activation. Molecular biology of the Cell. 4th edition. New York, Garland Science, 2002.

22. Ferrari L, Martelli P, Saleri R, De Angelis E, Cavalli V, Bresaola M, Benetti M and Borghetti P: Lymphocyte activation as cytokine gene expression and secretion is related to the porcine reproductive and respiratory syndrome virus (PRRSV) isolate after in vitro homologous and heterologous recall of peripheral blood mononuclear cells (PBMC) from pigs vaccinated and exposed to natural infection. Vet Immunol Immunopathol 151: 193-206, 2013.

23. Bachmann MF and Oxenius A: Interleukin 2: From immunostimulation to immunoregulation and back again. EMBO Rep 8: 1142-1148, 2007.

24. Zhu J and Paul WE: Peripheral CD4+ T-cell differentiation regulated by networks of cytokines and transcription factors. Immunol Rev 238: 247-262, 2010.

25. Nishimoto $\mathrm{N}$ and Kishimoto T: Interleukin 6: From bench to bedside. Nat Clin Pract Rheumatol 2: 619-626, 2006.

26. Riether C, Schürch CM and Ochsenbein AF: Regulation of hematopoietic and leukemic stem cells by the immune system. Cell Death Differ 22: 187-198, 2015. 
27. Zhou X, Schmidtke P, Zepp F and Meyer CU: Boosting interleukin-10 production: Therapeutic effects and mechanisms. Curr Drug Targets Immune Endocr Metabol Disord 5: 465-475, 2005.

28. Shevach EM, DiPaolo RA, Andersson J, Zhao DM, Stephens GL and Thornton AM: The lifestyle of naturally occurring CD4+ CD25+ Foxp3+ regulatory T cells. Immunol Rev 212: 60-73, 2006.

29. Ouyang W, Kolls JK and Zheng Y: The biological functions of T helper 17 cell effector cytokines in inflammation. Immunity 28 : 454-467, 2008.

30. Onishi RM and Gaffen SL: Interleukin-17 and its target genes: Mechanisms of interleukin-17 function in disease. Immunology 129: 311-321, 2010.

31. Yi T, Zhao D, Lin CL, Zhang C, Chen Y, Todorov I, LeBon T, Kandeel F, Forman S and Zeng D: Absence of donor Th17 leads to augmented Th1 differentiation and exacerbated acute graft-versus-host disease. Blood 112: 2101-2110, 2008.
32. Khanum F, Bawa AS and Singh B: Rhodiola rosea: A Versatile Adaptogen. Compr Rev Food Sci F 4: 55-62, 2005.

33. Brown RP and Gerbarg PL: Rhodiola rosea: A Phytomedicinal Overview. HerbalGram 56, 2002.

34. Skopińska-Rózewska E, Stankiewicz W, Zdanowski R, Siwicki AK, Furmanowa M, Buchwald W and Wasiutyński A: The in vivo effect of Rhodiola quadrifida extracts on the antibody production, on the blood leukocytes subpopulations and on the bacterial infection in mice. Centr Eur J Immunol 37: 140-144, 2012.

35. Mishra KP, Chanda S, Shukla K and Ganju L: Adjuvant effect of aqueous extract of Rhodiola imbricata rhizome on the immune responses to tetanus toxoid and ovalbumin in rats. Immunopharmacol Immunotoxicol 32: 141-146, 2010.

36. Bień K, Lewicki S, Zdanowski R, Skopińska-Różewska E and Krzyżowska M: Feeding pregnant and lactating mice Rhodiola kirilowii extracts helps to preserve thymus function of their adult progeny. Pol J Vet Sci 19: 581-587, 2016. 